\title{
CONFLITO AGRÁRIO ENTRE ÍNDIOS E AGRICULTORES FAMILIARES DO NORTE DO RIO GRANDE DO SUL - BRASIL
}

\author{
Raquel BREITENBACH ${ }^{1}$ \\ Alessandra TROAIN ${ }^{2}$ \\ ${ }^{1}$ Mestre e Doutora em Extensão Rural (UFSM), Professora do IFRS - Instituto Federal de Educação, Ciência e \\ Tecnologia do Rio Grande do Sul, Câmpus Sertão. E-mail: raquel.breitenbach@ sertao.ifrs.edu.br. \\ ${ }^{2}$ Bacharel em Desenvolvimento Rural e Gestão Agroindustrial (UERGS), Mestre em Extensão Rural (UFSM), Doutora \\ em Desenvolvimento Rural (UFRGS). E-mail: xatroian@gmail.com. \\ Recebido em: 22/05/2014 - Aprovado em: 30/06/2014 - Disponibilizado em: 30/07/2014

\begin{abstract}
Resumo
A questão agrária brasileira é marcada por conflitos e desigualdades históricas que geraram problemas econômicos e sociais. Dentre estes, pode-se destacar os conflitos fidedignos entre indígenas e agricultores pela posse de terras agricultáveis. Na região Norte do Estado do Rio Grande do Sul, Brasil existem 11 áreas envolvendo aproximadamente 16 municípios, com conflitos entre agricultores e indígenas entorno de demarcações, desapropriações e posse de terras. Neste sentido, o objetivo do presente estudo é investigar as impressões legais e históricas dos fatos e dos agentes (agricultores, comunidade indígena, população em geral) envolvidos no conflito em questão. Como resultados, observase que existem fatos históricos e legais comprobatórios das ações jurídicas indicativas de desapropriação dos agricultores. Já acerca das impressões dos agentes, estes divergem suas opiniões especialmente com base na sua relação com o caso, conhecimento histórico e legal acerca do mesmo, bem como seus interesses econômicos.
\end{abstract}

Palavras Chaves: Indígenas. Agricultores. Conflitos agrários.

\section{AGRARIAN CONFLICT BETWEEN INDIANS AND FAMILY FARMERS BY TENURE OF LAND IN NORTHERN OF RIO GRANDE DO SUL STATE, BRAZIL}

\begin{abstract}
The Brazilian agrarian question is marked by conflicts and historical inequalities that generate economic and social problems. Among these, we can highlight the trusted conflicts between indigenous farmers and the ownership of agricultural land. In the northern state of Rio Grande do Sul, Brazil there are 11 areas involving approximately 16 municipalities, with conflicts between farmers and indigenous peoples around demarcations, expropriations and land ownership. In this sense, the objective of this study is to investigate the legal and historical impressions of facts and agents (farmers, indigenous community, general public) involved in the conflict in question. As a result, it is observed that there are legal actions evidencing indicative of expropriation of farmers historical and legal facts. Already on impressions of the agents, they diverge their opinions especially based on their relationship to the case, historical and legal knowledge about the same, as well as their economic interests.
\end{abstract}

Key Words: Indigenous. Farmers. Agrarian conflicts.

1 INTRODUÇÃO

O Brasil possui algumas particularidades quando o assunto é distribuição, posse e acesso a terra, as quais marcaram a história do país e ditam a atual situação fundiária. De uma forma simplificada, todo processo de desenvolvimento brasileiro se estabeleceu através de estreitas relações entre terra e 
capital, trazendo algumas implicações, entre elas as que vamos explorar no decorrer desse artigo. De uma forma especial, pode-se destacar que no Brasil a propriedade da terra sempre representou e ainda representa poder para quem a tem, já que a partir dela também se tem acesso ao capital e proteção da política e dos governantes.

As implicações dessa apertada relação entre terra e poder se refletem num país altamente desigual, tanto no campo quanto na cidade. Além disso, o acesso a terra é limitado, gera conflitos, disputas e mortes. $\mathrm{Ou}$ seja, terra é sinônimo de capital, de produção, de lucros e não de meio de vida, de local para cultuar tradições, respeitar culturas.

A questão agrária brasileira, portanto, é marcada por conflitos e desigualdades históricas que geraram problemas econômicos e sociais. Dentre estas, destaca-se os conflitos fidedignos entre indígenas e agricultores pela posse de terras agricultáveis. Em 2011 a Comissão Pastoral da Terra lançou um relatório sobre conflitos no campo a partir de dados coletados em 2010 em que constatou que dos 638 conflitos, mais da metade referese a posseiros (antigos donos de pequenas áreas sem títulos da propriedade) e a povos e comunidades tradicionais (indígenas, quilombolas, extrativistas etc.) - totalizando $57 \%$ das violências ligadas a terra, no ano. A maior parte dos casos tem sua causa ligada a grandes projetos, como barragens, ferrovias, rodovias, parques eólicos e mineração
$\mathrm{Na}$ região Norte do Estado do Rio Grande do Sul existem 11 áreas, envolvendo aproximadamente 16 municípios, com conflitos entre agricultores e indígenas entorno de demarcações, desapropriações e posse de terras. Para tais áreas, o Ministério Público Federal (MPF) destaca haver indícios suficientes da ancestralidade da ocupação dos indígenas no local. Portanto, o MPF aponta a necessidade de produção de prova pericial antropológica para demonstrar a titularidade do domínio da terra em litígio pelos produtores.

Por outro lado, os agricultores possuem escritura de suas terras a mais de um século e, em caso de desapropriação, não teriam garantida a indenização das áreas. Dessa forma, seriam impedidos de permanecer na atividade agropecuária, que é o único "know how" para a maioria dos agricultores envolvidos, rompendo vínculos culturais e religiosos com o local.

Esse contexto é responsável pela intranquilidade e tensão, bem como divide opiniões entre os atores locais. Dessa forma, o presente estudo objetiva investigar as impressões legais e históricas dos fatos e dos agentes (agricultores, comunidade indígena, população em geral) envolvidos no conflito entre agricultores e comunidade indígena no município de Getúlio Vargas, RS, Brasil. Metodologicamente realizou-se um estudo exploratório com fins de observação, na tentativa de compreender o posicionamento, (MANFREDO, 2011). 
opiniões e percepções dos envolvidos, acerca desse conflito.

\section{METODOLOGIA}

Com base nas características e na natureza da investigação, esse estudo se enquadra numa pesquisa qualitativa e utiliza como método o estudo de caso. Por aprofundar-se no mundo dos significados das ações e relações humanas, a pesquisa qualitativa estuda o lado não perceptível em equações, médias e estatísticas (MINAYO, 1994).

A pesquisa qualitativa busca a compreensão detalhada dos significados e características situacionais apresentados pelos objetos de pesquisa, em vez da produção de medidas quantitativas de características ou comportamentos (RICHARDSON, 1999).

Por outro lado, o estudo de caso é um método de pesquisa supõe que se pode adquirir conhecimentos do fenômeno estudado a partir de uma exploração intensa de um único caso. "O estudo de caso não é uma técnica específica, mas uma análise holística, e mais completa possível, que considera a unidade social estudada como um todo, seja um indivíduo, uma família, uma instituição ou uma comunidade, com o objetivo de compreendê-los em seus próprios termos" (GOLDENBERG, 2003, p. 33).

Como técnicas de pesquisa foram utilizadas a revisão de materiais bibliográficos e secundários, para compor o corpo teórico e empírico do trabalho. Também utilizou-se a técnica da entrevista e da observação. A entrevista é considerada como um importante instrumento de trabalho nos vários campos das ciências sociais, ou outros setores como pesquisas de mercado. (MARCONI; LAKATOS, 2003). Já a observação, é uma técnica de coleta de dados para conseguir informações e utiliza os sentidos na obtenção de determinados aspectos da realidade. Não consiste apenas em ver e ouvir, mas também em examinar fatos ou fenômenos que se deseja estudar. Observar um fenômeno é reconhecer que este foi separado de seu contexto para que sejam estudados em seus atos, nas atividades, significados, relações, etc. Os fenômenos são individualizados ou agrupados dentro de uma realidade que é indivisível, na busca do "descobrimento" dos seus aspectos aparentes e profundos (TRIVINÕS, 1987).

Para tanto, a observação deu-se no período de julho a dezembro de 2012. Observaram-se, especialmente, conversas informais entre diversos agentes sobre o conflito, nas quais cada um deles expressava e defendia as suas opiniões. Além disso, foram realizadas entrevistas informais com informantes chaves da região, a saber: agricultores envolvidos diretamente na disputa, professores/pesquisadores que trabalham com a comunidade indígena e estudam sua cultura e tradições e comerciantes locais. 


\section{2,1 Breve caracterização do município de} Getúlio Vargas/RS

Getúlio Vargas foi elevado à categoria de município pelo Decreto n. $^{\circ}$ 5.788, de 18 de dezembro de 1934, desmembrando-se dos municípios de Erechim e Passo Fundo. Os limites territoriais de Getúlio Vargas, ao norte, são os municípios de Erechim, Áurea e Centenário, ao sul o município de Sertão. Ao leste, a divisa é com Floriano Peixoto e Charrua e a oeste com Erebango e Estação.

A colonização do município é basicamente de imigrantes, na maioria italiana, alemã e polonesa, que chegaram à região por volta de 1900. A população municipal, segundo dados do Instituto de Geografia e Estatística - IBGE (2010) é de 16.154 habitantes, sendo 2.292 habitantes rurais e urbanos 13.864, distribuídos em uma área de $286 \mathrm{Km}^{2}$.

A principal atividade econômica no município de Getúlio Vargas é a indústria, logo em seguida aparece à agropecuária. $\mathrm{Na}$ agricultura, destaca-se a produção de soja, milho, trigo e cevada, já na pecuária, destacase a criação de suínos, a produção de gados e ovinos para corte e leite. Também é desenvolvida a criação de frangos tanto de corte como de postura

O município caracteriza-se pela presença da agricultura familiar, sendo o módulo fiscal estabelecido em 20 hectares, pelas áreas planas e propícias para a mecanização. Razões essas que desencadeiam na valorização e disputa das áreas de terra.

\section{QUESTÕES LEGAIS E HISTÓRICAS DA POSSE DE TERRAS NO BRASIL}

É normal que a sociedade apresente problemas econômicos, os quais envolvem perguntas clássicas sobre "o que, como e para quem produzir", as quais, tradicionalmente fazem parte dos estudos sobre o funcionamento dos mercados e dos governos. Em situações nas quais o mercado é incapaz de alocar recursos eficientemente, surge a necessidade da intervenção governamental. Essas análises tratam os agentes da sociedade como se eles aceitassem pacificamente alterar a alocação de direitos de propriedade (ARAUJO JUNIOR, SHIKIDA; ALVARENGA, 2008).

Destaca-se que existe uma terceira forma de se alocar recursos além das tradicionais trocas voluntárias (mercado) e involuntárias, mas consentidas (governo/sistema político), que é a troca involuntária e não consentida, que se refere às alocações realizadas sem o respeito aos direitos de propriedade previamente estabelecidos. Exemplo disso é a invasão de um terreno, sem autorização de seu dono ou das autoridades legais, o assalto à mão armada, entre outros. 
Desta situação é que emerge o discurso dos invasores de terra (DI TELLA, GALIANI; SCHARGRODSKY, 2005). Bem como argumentam Alston, Libecap e Mueller (1999) que a busca por terra pode ser pensada como uma disputa por direitos de propriedade. Os autores destacam ainda, que incentivos econômicos e políticos influenciam na decisão de se intensificar ou não o conflito no campo.

Dentro desse contexto de conflitos no campo, destaca-se a importância histórica da Lei de Terras de 1850. Christillino (2008) destaca que a Coroa Portuguesa na época de aplicação de tal Lei não pressionou os fazendeiros a cumprirem os trâmites previstos na Lei de Terras - registros paroquiais, processos de legitimação e revalidação, bem como titulação das áreas - e, dessa forma, não impôs seu projeto.

A Lei de Terras foi regulamentada pelo decreto n. 318, de 20 de janeiro de 1854, conhecido como Regulamento de 1854, constituído de 108 artigos. O decreto descentralizou as legitimações e revalidações de terras ao delegar ao juiz comissário a condução das medições e de outras etapas dos autos, como a verificação de cultura efetiva e morada habitual. O juiz comissário nomeava os agrimensores, os peritos para o exame da extensão e do estado de ocupação das posses e também os árbitros para a resolução de impasses que ocorressem durante a medição. Ao mesmo tempo, no Regulamento de
1854, o presidente de província, o ministro de Negócios do Império e o da Agricultura (pasta criada em 1860) foram incumbidos de importantes decisões em torno da regularização do acesso a terras e da resolução de litígios.

No Regulamento, estabeleceu-se a criação das repartições especiais de terras públicas nas províncias, as quais coordenariam os trabalhos referentes às medições das terras particulares e às demarcações das áreas públicas em cada uma delas. Na província do Rio Grande do Sul, a Repartição Especial de Terras Públicas foi criada em 1855 e transformada em Diretoria de Terras Públicas e Colonização em 1872. Contudo, as decisões das repartições estavam sempre sujeitas à aprovação do presidente de província. Também foi criada a Repartição Geral de Terras Públicas, encarregada de dar parecer sobre todas as questões que envolviam a Lei de Terras e também sobre aquelas nas quais estivessem envolvidos os interesses do Estado. Era o caso da demarcação de terras para o estabelecimento de colônias, o aldeamento de indígenas e a venda de terras públicas (CHRISTILLINO, 2008, p.235).

Porém, a conturbada conjuntura política da época coagia os gabinetes conservadores a evitarem a imposição de políticas do Governo Imperial que viessem a contrariar os interesses dos fazendeiros. Já na sua regulamentação, a Lei de Terras não foi cumprida como deveria sobre a estrutura 
fundiária do Brasil, na medida em que seus dispositivos coibiam as apropriações abusivas e irregulares de terras. Ou seja, a regulamentação da Lei de Terras mostra que sua aplicação foi redirecionada para não impor os processos de legitimação e revalidação aos fazendeiros, porque isso questionaria seu direito de propriedade (CHRISTILLINO, 2008).

$\mathrm{O}$ autor supracitado concluiu, portanto, que os processos de legitimação mostram que a Repartição Especial de Terras Públicas, mais tarde transformada na Diretoria de Terras Públicas e Colonização, tinha meios de descobrir e coibir as apropriações abusivas das terras públicas. Porém, cabia ao presidente provincial o julgamento final dos processos, o que oferecia margem à negociação política para afirmação de propriedade. Ou seja, a Lei de Terras constituiu um importante poder de barganha da Coroa junto às elites locais. Esse fato é fundamental à afirmação do poder político do Governo Imperial, especialmente na província do Rio Grande do Sul, cuja elite miliciana era essencial à manutenção da hegemonia do Império no Prata e também à preservação da ordem interna.

No que se refere ao termo "posse", O Código Civil disciplina a posse nos artigos 1.196 a 1.224 , no título I, do Livro III, onde se distribuem as normas que disciplinam o direito das coisas. O Código Civil de 2002 adotou preponderantemente a teoria objetiva, no seu artigo 1.196, onde se lê que é "possuidor todo aquele que tem de fato o exercício, pleno ou não, de algum dos poderes inerentes à propriedade". Segundo Matos (2012), a interpretação deste artigo levou à afirmação comum de que a posse é a exteriorização da propriedade. Todavia, essa orientação nem sempre corresponde à exata verdade dos fatos.

Nem sempre quem possui a posse é proprietário. Portanto, a relação possessória pode ser apresentada em três diferentes situações: a) a posse aparece associada ao exercício do direito de propriedade, como no caso do possuidor proprietário; b) a posse que aparece paralelamente ao direito de propriedade, como no caso do usufrutuário, do locatário, dentre outros; c) a posse aparece em oposição ao direito do proprietário, como ocorre na usucapião, em que o proprietário perde o domínio da coisa "face ao reconhecimento da posse continuada de outrem." (DOMANSKY, 1998, p.44).

Com relação ao direito indígena às suas terras, lembra-se que ele consta na lei desde a Carta Regia de 30 de julho 1609. O Alvará de $1^{\circ}$ de abril de 1680 afirma que os índios são "primários e naturais senhores" de suas terras, e que nenhum outro título, nem sequer a concessão de sesmarias, poderá valer nas terras indígenas. Quanto ao direito constitucional, desde a Constituição de 1934, é respeitada a posse indígena inalienável das suas terras. Foi na bancada amazonense que teve origem a emenda que consagrou esses direitos em 1934. Todas as Constituições 
subsequentes mantiveram e desenvolveram esses direitos, sendo que a Constituição de 1988 deu-lhes sua expressão mais detalhada. Os índios têm direitos constitucionais, consignados em um capítulo próprio e em artigos esparsos da Constituição Federal de 1988. Conforme Cunha (1994), a Constituição trata, sobretudo de terras indígenas, de direitos sobre recursos naturais, de foros de litígio e de capacidade processual.

Além disso, Andrade, Dias e Quintella (2001) destacam a necessidade de procedimentos administrativos para demarcação de áreas tradicionalmente indígenas exigido pelo artigo 19 do ato 6001/73 e estabelecido pelos decretos presidenciais 22/91 e 1775/96; bem como que a Constituição Brasileira de 1988, que estabelece: Título II, Capítulo I, Artigo 5- a garantia do direito a propriedade; Título IV, Capítulo V, Artigo 129 - o Ministério Público Federal tem como uma de suas funções institucionais a defesa dos direitos e interesses dos índios de acordo com as regras do sistema judiciário; Título VIII, Capítulo VIII, Artigos 231 e 232 - o reconhecimento do direito dos índios às terras tradicionalmente ocupadas por eles e a legitimidade, em si, das organizações indígenas na defesa dos seus direitos e interesses.
4 IMPRESSÕES ACERCA DOS CONFLITOS ENTRE ÍNDIOS E AGRICULTORES EM GETULIO VARGAS/ RS

O município de Getúlio Vargas tem uma economia que depende de forma predominante do setor agropecuário, sendo que as propriedades rurais envolvidas no conflito com indígenas pela posse de terras têm importante participação na geração de renda, impostos e alimentos. De modo geral, as unidades de produção são de caráter familiar e os agricultores descendentes de imigrantes alemães e italianos, que têm como única atividade econômica a agricultura.

Os índios, por outro lado, foram "espremidos" numa área restrita de terra e encontram-se ameaçados culturalmente, já que diferente dos agricultores familiares da região, eles não praticam atividades agrícolas intensivas, vivem da caça, pesca e da coleta de frutos. A terra em quantidade, sem buscar a produtividade é uma questão cultural desse povo.

Para entender melhor o conflito analisado, destaca-se que o mesmo segue como principais processos: Primeiramente, em 16/07/2004 a Fundação Nacional do Índio (FUNAI), criou um Grupo Técnico (GT) que iniciou a demarcação de área indígena, que abrangeria parte dos municípios de Erechim, Erebango e Getúlio Vargas. Num segundo momento, o GT elaborou um laudo técnico, que foi contemplado pelo presidente da FUNAI e publicado no Diário Oficial da União no dia 23/11/2009.

Posteriormente, os agricultores apresentaram sua defesa na fase administrativa em março de 2010 , o chamado contra laudo, o qual contestou o laudo e 
acusou o mesmo de ser falho e inconsistente. Segundo os agricultores, os argumentos apresentados pelos antropólogos não convenciam. Além disso, alguns rituais próprios e culturais dos índios foram utilizados para explicar e justificar que estes eram os reais donos das terras. Sendo negado o contra laudo, a FUNAI solicitou ao Ministério de Justiça a demarcação da área de 4.230 ha em 30/09/2012, sendo decretada a demarcação da área em 26/09/2012, pelo mesmo ministério.

Por fim, os produtores rurais, representados por sua acessória jurídica, entraram com uma ação da justiça federal em 11/10/2012, visando suspender os efeitos do decreto do Ministro. A partir daí será discutido o mérito da questão. Na justiça tentarão provar que a referida área foi colonizada já no início do século passado (1905 a 1933) por agricultores que possuem documentação legal e histórica de suas propriedades e posses; portanto, não se trata de área tradicionalmente ocupada por comunidade indígena. A expectativa é de uma longa batalha judicial.

O conflito no norte do Rio Grande do Sul provoca um clima de tensão entre agricultores, índios e governo federal. O Ministério da Justiça decretou a demarcação da área de 4.230 hectares da Pretensa Reserva Indígena do Mato Preto. Desta área 4\% estão situados no município de Erechim, 9\% em Erebango e $87 \%$ em Getúlio Vargas. Destacase que o laudo apresentado pela FUNAI em
2009 pretende desalojar mais de 300 famílias para assentar 63 índios Guaranis na área.

Apesar das contestações dos produtores, a demarcação foi aprovada pelo Ministério da Justiça e também pelo Ministério Público Federal. O cacique Joel Kuaray afirma que aguarda a terra para gerar renda e também para a subsistência das próprias famílias indígenas (AZEREDO, 2012).

O procurador do Estado do Rio Grande do Sul Rodinei Candeia é contrário a demarcação e aponta que houve fraude nos laudos encaminhando à Justiça Federal, fazendo uma apelação contra a decisão. Segundo o procurador, a área demarcada para os indígenas seria inicialmente de 223 hectares e não os quatro mil hectares determinados pelo laudo. Além disso, caso a decisão seja a favor da comunidade indígena, as famílias de agricultores devem ser indenizadas, no entanto, há dúvidas quanto ao pagamento (AZEREDO, 2012).

A Federação dos Trabalhadores na Agricultura no Rio Grande do Sul (FETAG) classifica as demarcações como uma "reforma agrária às avessas", já que diversas famílias terão que deixar as terras, mesmo vivendo e produzindo nelas há mais de três gerações. A preocupação da FETAG é a claridade dos laudos antropológicos, sendo que um sociólogo foi contratado para ajudar a entidade a revisá-los. Para a Fundação Nacional do Índio, a contar de 10/2012, em sete meses os agricultores que moram nos 4,2 
mil hectares da área delimitada como Mato Preto devem deixar as terras, para as famílias de guaranis tomem posse das propriedades (MAIOR, 2012).

No que se refere à disputa existente, Azanha (2005) destaca que o problema para a revisão dos limites de terras indígenas reconhecidas por atos de estados federados há mais de 80 anos, é que as terras de anterior e integral ocupação indígena, foram tratadas como devolutas e então transferidas para particulares. Portanto, os índios ficaram impedidos legalmente de usufruírem dos recursos naturais nas glebas transferidas a particulares.

$\mathrm{O}$ autor explica que nas regiões Sul, Sudeste e Nordeste do Brasil, a pressão sobre as terras indígenas por força da colonização neo brasileira consolidou-se no Segundo Império, confinando os povos indígenas em pequenas glebas de terras - já então reduzidos em suas populações em função das doenças trazidas pelo contato ou pela ação dos "bugreiros", como pode ser visualizado no caso descrito no presente estudo. Estas glebas seriam posteriormente "concedidas" pelos estados federados ao extinto Serviço de Proteção aos Índios (SPI), nos anos 19201940, para o estabelecimento de reservas indígenas, consolidando juridicamente a situação de confinamento. Ocorre, porém, que os procedimentos legais adotados pela maioria dos estados daquelas regiões se amparavam em uma interpretação errônea da
Lei 601, pois consideraram devolutas as terras de ocupação tradicional indígena.

Portanto, distorcendo o objetivo da Lei 601, os estados federados, após o estabelecimento da República e da Constituição de 1891, em que o artigo 64 transferia para os estados as terras devolutas, passaram a considerar como se devolutas fossem terras de ocupação primária dos índios e dos aldeamentos não extintos.

Quanto a isso, alerta Mendes Junior (1988, p. 59):
[...] a ocupação, como título de aquisição, só pode ter por objeto as coisas que nunca tiveram dono, ou que foram abandonadas por seu antigo dono. A ocupação é uma apprehensio rei nullis ou rei derelictoe $[\ldots]$; ora, as terras de índios, congenitamente

apropriadas, não podem ser consideradas nem como res nullis nem como res derelictoe; por outra, não se concebe que os índios tivessem adquirido, por simples ocupação, aquilo que lhes é congênito e primário de sorte que, relativamente aos índios estabelecidos, não há uma simples posse, há um título imediato de domínio; não há portanto, posse a legitimar, há domínio a reconhecer e direito originário

preliminarmente

reservado[...] o indigenato não é um fato dependente de legitimação, ao passo que a ocupação, como fato posterior, depende de requisitos que a legitimem.

A incorporação por parte dos Estados

para seu domínio privado, como terras 
devolutas, das terras dos índios, constituiu privo do patrimônio indígena. Portanto, as glebas de anterior ocupação indígenas foram transferidas à particulares por procedimentos cartoriais ilegais, já que desconsideraram a posse indígena tal como definida na Lei de Terras, o que pode ser demonstrável no exame dos processos de legitimação das "posses" (AZANHA, 2005).

É importante entender esses processos para compreender a história do local de análise, mas também, para a definição de identidade étnica. Cunha (1994) destaca que toda a questão indígena está infetada de semelhantes reificações. No século XVI, os índios eram enquadrados como bons selvagens para uso na filosofia moral europeia, ou como detestáveis antropófagos para uso na colônia.

Observa ainda a autora, que desde os anos 1980, a previsão do desaparecimento dos povos indígenas cedeu lugar à constatação de uma retomada demográfica geral. Além disso, o grande contingente populacional indígena localiza-se na Amazônia, pela simples razão de que grande parte da região ficou à margem, nos séculos passados, dos surtos econômicos. $\mathrm{O}$ que se prova até pelas exceções: onde houve borracha, por exemplo, no Acre, as populações e as terras indígenas foram duramente atingidas e a maior parte dos sobreviventes dos grupos pano do Brasil hoje estão em território peruano. Defende-se, portanto, que as populações indígenas encontram-se onde a predação e a espoliação permitiu que eles ficassem (CUNHA, 1994).

Independente das questões legais, também é evidente que tanto agricultores quanto indígenas construíram uma identidade com o local. São gerações que cresceram naquelas terras, que se identificam com o território, e independente de quem tiver a posse da terra, sem dúvida haverá perdas sociais e culturais, além das questões econômicas.

Os agricultores moradores de Getúlio Vargas e região destacam que se forem desapropriados não serão indenizados, o que os impossibilitará de continuar desenvolvendo atividades agrícolas em outro local, sendo os conhecimentos ligados às atividades agrícolas os únicos que estas famílias possuem. Além disso, as áreas de terra foram adquiridas através de compra, os agricultores pagaram por elas, sem conhecimento de que as mesmas pudessem estar envolvidas em ilegalidades. No mais, eles exigem que o Estado reconheça a sua culpa nesse processo e faça algo em favor dos agricultores e de sua sustentabilidade econômica, social e cultural, profundamente ameaçada a partir desse conflito.

Os indígenas, reconhecidamente têm direito soberano sobre as terras em disputa e exigem imediata posse das mesmas. Especialmente, porque vivem em situação contestável, em área restrita e em situação de pobreza, sem acesso as condições mínimas de 
qualidade de vida, não usufruindo dos seus direitos legais.

Além dos indígenas e alguns atores sociais, poucos reconhecem a riqueza cultural dos índios. De maneira geral, a população do município de Getúlio Vargas é contrária à desapropriação da área dos agricultores e entrega da posse das terras para os indígenas. Os índios são considerados preguiçosos e desinteressados, dessa forma, a devolução das terras a eles é percebida como um desperdício, já que esses não explorariam as terras e não gerariam riquezas econômicas.

Os comerciantes locais temem que a transferência da posse das terras aos indígenas reduza a demanda de produtos industrializados, uma vez que os agricultores envolvidos são, de um modo geral, capitalizados, consumidores no comércio local, fazendo girar recursos na economia. Pode-se inferir que além das questões sociais, instalou-se no município a preocupação de cunho econômico, o comércio local teme a redução da circulação de mercadorias e rendas.

\section{CONSIDERAÇÕES FINAIS}

O Brasil é reconhecido pela enorme desigualdade social e pela histórica concentração de terra. Neste sentido, torna-se evidente que o país tem problemas em fazer cumprir o que está estabelecido na Lei. A histórica questão agrária, marcada por desigualdades e ilegalidades compromete o desenvolvimento do país como um todo.

A disputa entre agricultores e indígenas não é um caso isolado na região de Getúlio Vargas, no estado do Rio Grande do Sul, bem pelo contrário, tem-se observado um contexto de disputas e busca dos direitos em diversos estados da federação. Isso se deve, especialmente, pela ineficiência da União no cumprimento das leis, sobretudo, as leis referentes ao uso à posse de terras, como a Lei de Terras e a própria Constituição Brasileira de 1988.

O caso analisada parece estar longe de um desfecho, bem como dificilmente se obterão consensos de opinião sobre a questão em voga. Diversos são os interesses em jogo por trás de cada opinião dada, bem como se percebe a existência da falta ou a (dês) informação por parte dos agentes e dos agricultores.

Por fim, espera-se que o presente conflito não resulte em mortes e assassinatos, a exemplo do que ocorreu em Faxinalzinho no norte do estado do Rio Grande do Sul, em maio de 2014. Espera-se que o conflito seja utilizado de forma positiva e que a partir dele se obtenham avanços não só nos aspectos legais, mas também na valorização aos diferentes e distintos povos e as culturas envolvidas. 
terras-indigenas-provoca-tensao-no-norte-do-

rs-3913513.html>. Acesso em: 22 mai. 2014.

ALSTON, L., LIBECAP, G., MUELLER, B. Violence and the Development of Property Rights to Land in the Brazilian Amazon. In: NYE, J.V.C. AND DROBAK, J.N. Frontiers of the New Institutional Economics. Academic Press, San Diego, p.145-164, 1997.

ALSTON, L.J., LIBECAP, G.D., MUELLER, B. How Interest Groups with Limited Resources can Influence Political Outcomes: Information Control and the Landless Peasant Movement in Brazil. Institute of Behavioral Science, Working Paper, 2005.

ANDRADE, J. C. S.; DIAS, C. C.; QUINTELLA, R. H. A Dimensão PolíticoInstitucional das Estratégias Sócio Ambientais: o jogo Aracruz Celulose S.A. índios Tupiniquim e Guarani. Ambiente \& Sociedade, São Paulo, v. 4, n. 9, 2001.

AZANHA, G. As terras indígenas Terena no Mato Grosso do Sul. Revista de Estudos e Pesquisas, FUNAI, Brasília, v.2, n.1, p.61111, jul. 2005.

AZEREDO, D. Suspeita de fraude em demarcação de terras indígenas provoca tensão no norte do RS. 2012. Disponível em:<

http://agricultura.ruralbr.com.br/noticia/2012/
CHRISTILLINO, C. L. A tensão nos ervais: a resistência dos homens livres e pobres frente ao avanço da imigração no Rio Grande do Sul. Saeculum, UFPB, v. 18, p. 143-160, 2008.

CUNHA, M. C da. O futuro da questão indígena. Estudos Avançados, São Paulo, v.8, n. 20, p. 121-136, 1994.

CUNHA, M. C. da. Os direitos dos índios. São Paulo: Brasiliense, 1987.

DI TELLA, R., GALIANI, S.; SCHARGRODSKY, E. Property Rights and Beliefs: Evidence from the Allocation of Land Titles to Squatters. Ronald Coase Institute. Working Paper. 2005. Disponível em:<http://federation.ens.fr/ydepot/semin/text e0506/TEL2005PRO.pdf>. Acesso em: 15 jan. 2014.

GOLDENBERG, M. A arte de pesquisar: como fazer pesquisa qualitativa em Ciências Sociais. 7 ed. Rio de Janeiro: Record, 2003.

HIRHSLEIFER, J. The paradox of power. Economics and Politics, v.3, p.177-200. [Reproduzido em HIRSHLEIFER, J. The Dark Side of the Force, Cambridge University Press, 2001.

10/suspeita-de-fraude-em-demarcacao-de- 
INSTITUTO BRASILEIRO DE GEOGRAFIA E ESTATÍSTICA. IBGE.

Cidades: Getúlio Vargas. Disponível em:< http://www.cidades.ibge.gov.br/painel/painel. php?codmun $=430890 \&$ search $=\% 7 \mathrm{C} \% 7 \mathrm{Cinfo}$ gr\%E1ficos:-dados-gerais-domunic\%EDpio\&lang=>. Acesso em 21 mai. 2014.

MAIOR, M. ZERO HORA. Os protestos contra demarcações de terras indígenas no RS. 2012. Disponível em: http://jornalggn.com.br/blog/luisnassif/osprotestos-contra-demarcacoes-de-terrasindigenas-no-rs. Acesso em 04 abr. 2013.

MANFREDO, M. T. Os conflitos pela terra no Brasil. Com Ciência: Campinas, 2011.

MARCONI, M. A.; LAKATOS, E. M. Técnicas de Pesquisa. 5 ed. São Paulo: Atlas, 2002.

MATOS, S. T. de A. A Disputa judicial da posse sobre terras públicas: um estudo sobre a viabilidade da alegação incidental do domínio, na pendência da ação possessória, envolvendo particulares. RIDB, Lisboa, v. 1, n.1, p. 3579-3604, 2012.

MINAYO, M. C. et al. Pesquisa social: teoria, método e criatividade. Petrópolis: Vozes, 1994.
RICHARDSON, R. J. et al. Pesquisa social: métodos e técnicas. São Paulo: Atlas, 1999.

SHIKIDA, C.; ALVARENGA, P. S.; ARAUJO JUNIOR, A. F. de. Economia política da disputa por terras em Minas Gerais. RESR, Piracicaba, SP, v 46, n.3, p. 803-830, jul./set. 2008.

SKAPERDAS, S. Restraining the Genuine Homo Economicus: Why the Economy Cannot Be Divorced from Its Governance. Economics and Politics, Malden, v.15, n.2, p. 135-162, 2003.

TRIVINÕS, A. N. S. Introdução à pesquisa em ciências sociais. São Paulo: Atlas, 1987.

UMBECK, J. Might makes rights: a theory of the formation and initial distribution of property rights. Economic Inquiry, Long Beach, v.19, p. 38-59, 1981. 